\title{
Clinical Depressive Symptoms and Diabetes in a Binational Border Population
}

\author{
Nelda Mier, PhD, Anabel Bocanegra-Alonso, PhD, MD, Dongling Zhan, MS, \\ Suojin Wang, PhD, Steven M. Stoltz, MD, Rosa I. Acosta-Gonzalez, MS, and \\ Miguel A. Zuniga, DrPH, MD
}

Background: Depression affects more Hispanics with type 2 diabetes than other ethnic groups. This exploratory, binational study examined the prevalence and correlates of clinical depressive symptoms in Hispanics of Mexican origin with type 2 diabetes living on both sides of the Texas Mexico border.

Methods: Two binational samples, consisting of 172 adult patients of Mexican origin with type 2 diabetes in South Texas and 200 from the Northeastern region of Mexico, were compared. Logistic regression analyses were used to test personal and social correlates to clinical depressive symptoms.

Results: The rate of clinical depressive symptoms was similar in both South Texas and Northeastern Mexico patients (39\% and 40.5\%, respectively). Gender, education, emergency department visits, and burden of diabetes symptoms were predictors of clinical depressive symptoms in the South Texas sample. Among respondents in the Northeastern Mexico sample, the only statistically significant correlate to clinical depressive symptoms was the burden of diabetes symptoms.

Conclusions: Diabetes and depression must be addressed as priorities in diabetes initiatives at the US Mexico border region. Further research is warranted to examine the extent and impact of involving family practice physicians from both sides of the border in depression screenings among patients with type 2 diabetes. (J Am Board Fam Med 2008;21:223-233.)

Depression in patients with type 2 diabetes is associated with increased mortality rates, poor glycemic control, increased diabetes complications, increased functional disability, poorer compliance with treatment recommendations, and higher medical costs. ${ }^{1-4}$ A recent meta-analysis ${ }^{5}$ indicates that major depression and elevated depression symp-

This article was externally peer reviewed.

Submitted 13 November 2007; revised 18 February 2008; accepted 22 February 2008.

From the Department of Social and Behavioral Health, School of Rural Public Health (NM) and the South Texas Center (MAZ), Texas A\&M Health Science Center, and the Department of Statistics (DZ, SW), Texas A\&M, College Station; the Medicine Research Department (AB-A) and the Clinical Analyses Department (RIA-G), Unidad Académica Multidisciplinaria Reynosa-Aztlán, Universidad Autónoma de Tamaulipas, Mexico; and the South Texas Institutes of Health, McAllen (SMS).

Funding: This research was supported by the Texas Department of State Health Services and by Health Services Research Program (a collaborative research venture involving the TA\&M HSC School of Rural Public Health and the Scott and White Hospital and Clinic and the Scott and White Health Plan).

Conflict of interest: none declared.

Corresponding author: Nelda Mier, PhD, 2101 South McColl Road Room 134, McAllen, TX 78503 (E-mail: nmier@srph.tamhsc.edu). toms are present, respectively, in $11 \%$ and $31 \%$ of people with diabetes in the United States. Moreover, depression affects more Hispanics with type 2 diabetes than blacks and non-Hispanic whites with the same condition. ${ }^{6-8}$

Hispanics are the largest and fastest growing minority population in the United States ${ }^{9}$ and are disproportionately affected by type 2 diabetes and its related complications and comorbidities. ${ }^{10,11}$ The prevalence of diabetes in this minority group is 2 times higher when compared with whites. ${ }^{11,12}$ Hispanics with type 2 diabetes are also 2 times more likely to develop diabetes-related complications than non-Hispanic whites. ${ }^{13-16}$ The burden of diabetes in Hispanics is even more salient in the United States Mexico border area. Almost 16\% of border residents suffer from type 2 diabetes, a higher rate than the national rates both in Mexico $(7.5 \%)$ and the United States (13.9\%). ${ }^{17}$ Along the border, the diabetes death rate for Hispanics living in US counties (46.7 age-adjusted per 100,000 population) is 3 times the rate for non-Hispanic whites (16.3 age-adjusted per 100,000 population). ${ }^{18}$ On the Mexican side of the border, the diabetes prev- 
alence rate is higher than the national rate in Mexico (8.4\% and $7.5 \%$, respectively). ${ }^{19,20}$

Although depression is 2 times more prevalent in diabetic patients than the general population, ${ }^{2,5,21}$ the reasons for higher prevalence rates among diabetics are not fully understood. The cause of depression in patients with diabetes is difficult to identify because this condition may have biological roots, may be associated to the burden of complications, or a combination of both. ${ }^{22} \mathrm{~A}$ biopsychosocial approach proposed by Fisher et $\mathrm{al}^{23}$ suggests that multiple disease, personal, social, and community factors interact to affect depression in people with diabetes. Previous research about Hispanics with type 2 diabetes in the United Sates found that correlates to depression include age, ${ }^{8}$ education, ${ }^{8,23}$ financial stress, ${ }^{23}$ poorer self-rated health, ${ }^{24}$ diabetes-related functional impact, ${ }^{23}$ understanding and knowledge of diabetes, ${ }^{24}$ lifestyle behaviors, ${ }^{25}$ and poor glycemic control. ${ }^{26}$

Research examining depression and diabetes in patients along the United States Mexico border is warranted. High diabetes prevalence rates and related comorbidities in the border region not only affect patients' quality of life but also result in high economic costs for both the US and Mexico health care systems and communities. ${ }^{19,27}$ Although Healthy Border 2010 identifies diabetes and mental health issues as border priorities, ${ }^{28}$ the prevalence of depression in diabetics in the border region is unknown. The purpose of this study was to determine the levels and correlates of clinical depressive symptoms in Hispanic adult patients of Mexican origin with type 2 diabetes residing on both sides of the Texas Mexico border.

\section{Methods}

This was a cross-sectional study based on a survey conducted in 2004 to 2005 with 2 samples in the Lower Rio Grande Valley in South Texas and Reynosa in the Northern Tamaulipas region of Mexico. Using a convenience sampling technique, this study recruited people with type 2 diabetes from clinical settings on both sides of the border (hospitals and physicians' offices). Inclusion criteria included age of 18 years or older; diagnosis of type 2 diabetes for at least 1 year; and willingness to give informed consent. A total of 199 patients in South Texas and 200 in Northern Tamaulipas agreed to participate in the study. The recruitment sites in- cluded hospitals and physicians' offices. Staff from these facilities identified potential participants and asked them if they would be interested in participating in this study. The research team contacted these potential participants. In the case of the South Texas sample, participants were interviewed at a location of their convenience, usually at the physician's office or Texas A\&M headquarters. Participants in Northern Tamaulipas were interviewed at the hospital. In the analysis we only included participants of Mexican origin with complete data, resulting in a sample size of 172 from South Texas and 200 from Northern Tamaulipas. This study was approved by the Texas A\&M University Institutional Review Board.

\section{Measures}

Depressive symptoms were assessed using the Center for Epidemiologic Studies Depression Scale. This scale is a 20-item self-report depression inventory with possible scores ranging from 0 to 60 . Reliability and validity of the scale have been tested in general and clinical populations, yielding very good internal consistency, with an $\alpha$ of 0.85 for the general population and 0.90 for a patient population. Scale scores range from 0 to 60 . A cutoff point of 16 and above indicates clinically significant levels of depressive symptoms. ${ }^{29}$ Although the scale does not provide a diagnosis of clinical depression, it has been shown to predict both current and future clinical depression. ${ }^{30}$ The Center for Epidemiologic Studies Depression Scale has been validated in patients with diabetes, ${ }^{31}$ and the Spanish version has high validity and reliability (Cronbach's $\alpha$, $0.90) .^{32,33}$

Independent variables included demographic characteristics, health factors, health care use factors, and level of family support. Demographic variables included gender; age; marital status; country of origin (Mexico or United States, only applied to the South Texas sample); education level; socioeconomic status; and acculturation (only applied to the South Texas sample). Socioeconomic status was assessed by asking participants if they were employed or not; employment is an indicator of socioeconomic position. ${ }^{34,35}$ Household income was not included because of missing values. Acculturation was measured using the Short Acculturation Scale for Hispanics, a 12-item scale that has been validated in Spanish and has an internal reliability of $\alpha=0.92 .{ }^{36}$ Health factors were measured from 
self-report information and included the following: self-rated health status; age when diagnosed with diabetes; duration of diabetes; high blood pressure, heart disease, high cholesterol, insulin use, amputations, smoking, vision problems related to reading, driving, and watching TV; sexual function problems; leg discomfort limiting activities around the house, wearing wanted shoes, and sleeping; limited social life because of the need to follow a special diet; hypoglycemic symptoms; diabetes symptoms; patient's beliefs (including "sugar monitoring is painful," "taking medication or insulin is a waste of time," and "blood glucose level testing is difficult"). Body mass index was not included in the analyses because of missing values.

The burden of diabetes symptoms variable was measured using the Patient's Questionnaire Diabetes Form 2.1. ${ }^{37}$ This variable was calculated by summing 15 diabetes symptoms (from 0 to 15 ).

Use of health care factors included number of emergency department visits, doctor visits, hospital stays, diet counseling sessions, and diabetes education sessions during the past 12 months. Glucose level check was assessed asking the question, How many times do you check your blood sugar in an average week? (daily versus not daily).

Family support was measured using the Family Behavior Checklist, which assesses actions of a relative identified by the participant as the supportive person in their efforts to manage their diabetes. Scale items include the relative's supportive behaviors related to medication, glucose testing, exercise, diet, and in general. A positive summary score (high vs low family support) was obtained by averaging the frequency ratings over all 5 supportive items. Reliability and predictive validity of this scale is between 0.64 and 0.84 . The scale also asks the participant to rate the diabetes-related knowledge level of the supportive relative (low versus moderate versus high). ${ }^{38}$ The scale was translated into Spanish using a back-translation technique.

\section{Data Analyses}

Summary statistics were calculated to describe each sample in terms of sociodemographic and healthrelated variables. Demographic characteristics and health indicators between samples were compared using the Mann-Whitney $U$ test. Logistic regression analyses (unadjusted univariate and adjusted multivariate logistic regression) were used to test the association between the dependent variable (clinical depressive symptoms) and independent variables. The self-rated health status variable was not included in the logistic regression analyses because it was highly correlated with diabetes symptoms $(P<.01)$ in both samples. Including the self-rated health status variable in the multivariate regression may have distorted the results because of the colinearity problem in the regression fitting. Values of odds ratios, $95 \% \mathrm{CI}$, and $P$ were reported in the logistic regression analyses. The HosmerLemeshow goodness-of-fit test was conducted to test model fit. $P<.05$ was considered significant for all statistical tests conducted. The analyses were performed using the computer program SPSS version 13.0 for Windows (SPSS, Inc., Chicago, IL). ${ }^{39}$

\section{Results}

Table 1 shows the distribution of demographic characteristics and health measures for both samples and between-group differences. The majority of participants on both sides of the border were women, married, and had a low socioeconomic status. Almost half of the respondents in South Texas $(47.7 \%)$ were born in Mexico and the majority $(79 \%)$ had low levels of acculturation. Respondents in South Texas had a mean age of 57.8 (SD, 14.1) and the Northern Tamaulipas participants of 55.8 (SD, 12.2). Significantly more Northern Tamaulipas respondents were women and had less than a high school education than the South Texas participants.

The overall rate of clinical depressive symptoms was similar for both South Texas and Northern Tamaulipas patients $(39 \%$ and $40.5 \%$, respectively). There were no significant differences in clinical depressive symptoms between the samples. The majority of patients on both sides of the border reported having hypertension and high cholesterol. The majority in both samples also reported to perceive a high level of family support. Although the main source of family support for the South Texas participants was the spouse, for patients in Northern Tamaulipas it was both their spouse and children.

Compared with respondents in Northern Tamaulipas, significantly more South Texas participants reported better self-rate health status, but they also reported having high cholesterol. Conversely, significantly more patients in Northern Tamaulipas reported fewer physician visits in the past 12 months than did their South Texas counterparts. 
Table 1. Comparison of Demographic and Health Characteristics Between South Texas and Northern Tamaulipas Samples

\begin{tabular}{|c|c|c|c|}
\hline & South Texas $(\mathrm{n}=172)^{\dagger}\left(\mathrm{n}[\%]^{\ddagger}\right)$ & Northern Tamaulipas $(\mathrm{n}=200)^{\dagger}\left(\mathrm{n}[\%]^{\ddagger}\right)$ & $P$ \\
\hline \multicolumn{4}{|l|}{ Demographic characteristics } \\
\hline Gender* & & & .022 \\
\hline Female & $113(65.7)$ & $153(76.5)$ & \\
\hline Male & $59(34.3)$ & $47(23.5)$ & \\
\hline Marital status & & & .574 \\
\hline Married & $110(64.0)$ & $121(61.1)$ & \\
\hline Not married & $62(36.0)$ & $77(38.9)$ & \\
\hline Country of origin & & & .000 \\
\hline Mexico & $82(47.7)$ & $200(100)$ & \\
\hline United States & $90(52.3)$ & $0(0)$ & \\
\hline Education* & & & .007 \\
\hline$<$ High school & $98(57.0)$ & $140(70.4)$ & \\
\hline$\geq$ High school & $74(43.0)$ & $59(29.6)$ & \\
\hline Socioeconomic status & & & .245 \\
\hline Low & $127(74.7)$ & $158(79.8)$ & \\
\hline High & $43(25.3)$ & $40(20.2)$ & \\
\hline Acculturation & & & na \\
\hline Low & $137(79.3)$ & na & \\
\hline High & $35(20.3)$ & na & \\
\hline \multicolumn{4}{|l|}{ Health factors } \\
\hline CES_D scores $\$$ & & & .762 \\
\hline$<16$ & $105(61)$ & $119(59.5)$ & \\
\hline$\geq 16$ & $67(39)$ & $81(40.5)$ & \\
\hline Self-rated health status* & & & .000 \\
\hline Poor/Very poor & $25(14.6)$ & $57(28.6)$ & \\
\hline Fair & $49(28.7)$ & $87(43.7)$ & \\
\hline Good & $69(40.4)$ & $35(17.6)$ & \\
\hline Excellent/Very good & $28(16.4)$ & $20(10.1)$ & \\
\hline Hypertension & & & .310 \\
\hline Yes & $112(65.1)$ & $120(60.0)$ & \\
\hline No & $60(34.9)$ & $80(40.0)$ & \\
\hline Heart Disease & & $(0.053)$ & \\
\hline Yes & $55(32.0)$ & $46(23.0)$ & \\
\hline No & $117(68.0)$ & $154(77.0)$ & \\
\hline High Cholesterol* & & & .000 \\
\hline Yes & $107(63.7)$ & $79(39.7)$ & \\
\hline No & $61(36.3)$ & $120(50.3)$ & \\
\hline \multicolumn{4}{|l|}{ Amputations } \\
\hline Yes & $10(5.8)$ & $8(4.0)$ & \\
\hline No & $162(94.2)$ & $191(96.0)$ & \\
\hline Smoking & & & .207 \\
\hline Yes & $13(7.6)$ & $23(11.5)$ & \\
\hline No & $158(92.4)$ & $177(88.5)$ & \\
\hline Healthcare use & & & .273 \\
\hline \multicolumn{4}{|c|}{ Emergency room visits (past 12 months) } \\
\hline$\geq 1$ times & $51(29.7)$ & $70(35.0)$ & \\
\hline 0 & $121(70.3)$ & $130(65.0)$ & \\
\hline Doctor visits* (past 12 months) & & & .000 \\
\hline$\geq$ Once a month & $87(50.6)$ & $44(22.2)$ & \\
\hline$<$ Once a month & $85(49.4)$ & $154(77.8)$ & \\
\hline Hospital stays (past 12 months) & & & .625 \\
\hline$\geq 1$ & $51(29.7)$ & $64(68.0)$ & \\
\hline 0 & $121(70.3)$ & $136(32.0)$ & \\
\hline
\end{tabular}

*Significant difference between 2 groups using the Mann-Whitney $U$ test.

${ }^{\dagger}$ Because of missing data, the total number of individuals for each variable may be less than the total sample size.

‡Valid percent.

${ }^{\$}$ Center for Epidemiological Studies Depression Scale. Scale scores range from 0 to 60, and a cut-off point of 16 and above indicates clinical depressive symptoms.

na, not applicable. 
Table 2. Comparison of Diabetes-Related Characteristics Between South Texas and Northern Tamaulipas Samples

\begin{tabular}{|c|c|c|c|}
\hline Characteristic & $\begin{array}{l}\text { South Texas }(\mathrm{n}=172)^{\dagger} \\
\qquad\left(\mathrm{n}[\%]^{+}\right)\end{array}$ & $\begin{array}{l}\text { Northern Tamaulipas }(\mathrm{n}=200)^{\dagger} \\
\left(\mathrm{n}[\%]^{\ddagger}\right)\end{array}$ & $P$ \\
\hline Duration of Diabetes (mean[SD]) & $11.0(10.1)$ & $10.1(9.9)$ & .990 \\
\hline$\geq 10$ years & $75(44.4)$ & $88(44.4)$ & \\
\hline$<10$ years & $94(55.6)$ & $110(55.6)$ & \\
\hline Use of Insulin* & & & .000 \\
\hline Yes & $93(54.1)$ & $40(20.0)$ & \\
\hline No & $79(45.9)$ & $160(80.0)$ & \\
\hline Frequency of glucose monitoring* & & & .000 \\
\hline Daily & $130(75.6)$ & $8(4.1)$ & \\
\hline Not Daily & $42(24.4)$ & $189(95.9)$ & \\
\hline Diet counseling sessions* (past $12 \mathrm{mo}$ ) & & & .000 \\
\hline$\geq 2$ & $38(22.1)$ & $80(40.0)$ & \\
\hline 1 & $27(15.7)$ & $42(21.0)$ & \\
\hline 0 & $107(62.2)$ & $78(39.0)$ & \\
\hline Diabetes education sessions (past $12 \mathrm{mo}$ ) & & & .274 \\
\hline$\geq 2$ & $24(14.0)$ & $29(14.5)$ & \\
\hline 1 & $25(14.5)$ & $16(8.0)$ & \\
\hline 0 & $123(71.5)$ & $155(77.5)$ & \\
\hline \multicolumn{4}{|l|}{ Vision problems affecting: } \\
\hline Reading & & & .071 \\
\hline Yes & $93(54.1)$ & $126(63.3)$ & \\
\hline No & $79(45.9)$ & $73(36.7)$ & \\
\hline Driving & & & .294 \\
\hline Yes & $22(12.9)$ & $28(15.7)$ & \\
\hline No & $149(87.1)$ & $150(84.3)$ & \\
\hline Watching television & & & .007 \\
\hline Yes & $51(29.7)$ & $86(43.2)$ & \\
\hline No & $121(70.3)$ & $113(56.8)$ & \\
\hline Problems with sexual function & & & .347 \\
\hline Yes & $54(32.3)$ & $49(27.7)$ & \\
\hline No & $113(67.7)$ & $128(72.3)$ & \\
\hline \multicolumn{4}{|l|}{ Leg discomfort interferes with: } \\
\hline Home activities & & & .791 \\
\hline Yes & $88(51.2)$ & $98(49.5)$ & \\
\hline No & $84(48.8)$ & $100(50.5)$ & \\
\hline Wearing preferred shoes & & & .174 \\
\hline Yes & $66(38.4)$ & $88(44.7)$ & \\
\hline No & $106(61.6)$ & $109(55.3)$ & \\
\hline Sleep & & & .259 \\
\hline Yes & $55(32.0)$ & $74(37.2)$ & \\
\hline No & $117(68.0)$ & $125(62.8)$ & \\
\hline Special diet affects social life & & & .328 \\
\hline Yes & $57(33.1)$ & $56(28.4)$ & \\
\hline No & $115(66.9)$ & $141(71.6)$ & \\
\hline Diabetes Symptoms* (mean[SD]) & $6.36(3.52)$ & $6.91(3.18)$ & .000 \\
\hline Low sugar reaction (past $4 \mathrm{wk}$ ) & & & .063 \\
\hline Yes & $84(48.8)$ & $76(38.6)$ & \\
\hline No & $88(51.2)$ & $121(61.4)$ & \\
\hline "Glucose monitoring is painful"* & & & .022 \\
\hline Agree & $73(43.2)$ & $63(31.7)$ & \\
\hline Disagree & $96(56.8)$ & $136(68.3)$ & \\
\hline "Taking medication or insulin is a waste of time" & & & .689 \\
\hline Agree & $14(8.7)$ & $15(7.5)$ & \\
\hline Disagree & $147(91.6)$ & $184(92.5)$ & \\
\hline "Testing blood glucose is difficult"* & & & .038 \\
\hline Agree & $43(25.6)$ & $32(16.7)$ & \\
\hline Disagree & $125(74.4)$ & $160(83.3)$ & \\
\hline
\end{tabular}

*Significant difference between two groups using the Mann-Whitney U test.

${ }^{\dagger}$ Due to missing data, the total number of individuals for each variable may be less than the total sample size.

${ }^{\ddagger}$ Valid percent. 
Table 2 shows the distribution of diabetes-related characteristics for both samples and betweengroup differences. The majority of patients on both sides of the border reported being diagnosed with diabetes for less than 10 years and had not received any diabetes education during the past 12 months. Significantly more South Texas than Northern Tamaulipas respondents used insulin and believed that testing glucose level was painful and difficult. Conversely, significantly more patients in Northern Tamaulipas reported less frequent glucose level checks and a higher number of diabetes-related symptoms than their South Texas counterparts. There was also a significant difference between groups in relation to diet counseling, with more Northern Tamaulipas respondents than South Texas patients receiving 2 or more diet sessions during the past 12 months.

Table 3 shows the univariate (unadjusted) logistic regression analyses for each sample. Only variables that were statistically significant are listed in the table. Analyzed singly, the following variables had a statistically significant association with depression in both the South Texas and Northern Tamaulipas samples: gender; emergency department visits; hospital stays; diabetes symptoms (including leg discomfort interfering with sleep, home activities, and wearing preferred shoes); and limited social life because of having a special diet. Among South Texas participants, education level, high cholesterol, visits to the doctor more than once a month, vision problems that interfere with television watching, perception that glucose testing was difficult, and family support also had a statistically significant association with clinical depressive symptoms. Among Northern Tamaulipas participants gender; socioeconomic level; heart disease; vision problems that interfere with reading, driving, and watching television; and perception that glucose testing was difficult were statistically significantly correlated to clinical depressive symptoms.

Table 4 presents the results from the multivariate (adjusted) logistic regression analyses. Only significant associations are presented by sample. Among South Texas respondents, female gender, a low level of education, one or more emergency department visits during the past 12 months, burden of diabetes symptoms, having leg discomfort that interferes with wearing preferred shoes, and the perception that glucose testing was difficult were significantly correlated to clinical depressive symptoms. However, those reporting high cholesterol were less likely to have clinical depressive symptoms.

Among respondents in the Northern Tamaulipas sample the 2 items significantly associated with clinical depressive symptoms in the multivariate logistic model were the burden of diabetes symptoms and leg discomfort interfering with home activities. The estimated odds of having clinical depressive symptoms increased for each additional diabetes symptom by $27 \%$ for South Texas participants and $36 \%$ for the Northern Tamaulipas respondents.

\section{Discussion}

Our findings indicate that the prevalence of clinical depressive symptoms in both South Texas and Northern Mexico border residents with type 2 diabetes (39\% and $40.5 \%$, respectively) is higher than what is reported in the literature of clinical diabetic samples in the United States (32\%). ${ }^{5}$

Specifically, the prevalence rate of clinical depressive symptoms among South Texas respondents in our study was also higher than those reported in studies conducted with older Mexican Americans in Southwestern states $(25.6 \%$ to $31.1 \%)^{40,41}$ or Hispanic adult patients $(31.6 \%)$, ${ }^{6,23}$ but similar to a study with Hispanic women in South Florida (40.6\%). ${ }^{24}$ In the case of our border sample from the Mexican side, the clinical depressive symptoms prevalence rate found was similar to previous studies conducted in Central Mexico (37.91\% to $39 \%)^{25,42}$ but inconsistent with another study from Mexico City (46\%). ${ }^{43}$

Our study found that the strongest predictor of clinical depressive symptoms in type 2 diabetes patients on both sides of the Texas Mexico border was the burden of diabetes symptoms. Among respondents in Mexico this was the only predictor of depression. Our findings are in line with previous research in the United States. ${ }^{44-47}$ Our study, however, did not establish causation. Further research is needed to identify a causal pathway to determine how depression and the burden of diabetes symptoms interact. In addition, future research should investigate if identifying and treating depression in diabetic patients may result in a decreased burden of diabetes symptoms.

Additional significant correlates to clinical depressive symptoms in the South Texas sample were 
Table 3. Univariate Correlates to Clinical Depressive Symptoms by Two Study Samples

\begin{tabular}{|c|c|c|c|c|c|}
\hline \multirow[b]{2}{*}{ Significant Correlates* } & \multicolumn{2}{|c|}{ South Texas } & \multirow[b]{2}{*}{ Significant Correlates* } & \multicolumn{2}{|c|}{ Northern Tamaulipas } \\
\hline & OR (95\% CI) & $P$ & & OR $(95 \% \mathrm{CI})$ & $P$ \\
\hline Demographic factors & & & Demographic factors & & \\
\hline Gender & & & Gender & & \\
\hline Female & $2.50(1.25-5.00)$ & .010 & Female & $2.76(1.61-5.82)$ & .008 \\
\hline Male & 1.00 & & Male & $1.0(0)$ & \\
\hline Education & & & Education & & \\
\hline$<$ High school & $2.23(1.17-4.24)$ & .014 & $<$ High school & $2.39(1.09-5.21)$ & .029 \\
\hline$\geq$ High school & 1.00 & & $\geq$ High school & 1.00 & \\
\hline Health factors & & & Health factors & & \\
\hline High cholesterol & & & High cholesterol & & \\
\hline Yes & $0.39(0.20-0.74)$ & .004 & Yes & $2.08(1.07-4.06)$ & .031 \\
\hline No & 1.00 & & No & 1.00 & \\
\hline Burden of diabetes symptoms & $1.40(1.24-1.57)$ & .000 & Burden of diabetes symptoms & $1.45(1.27-1.64)$ & .000 \\
\hline Vision problems affect: & & & Vision problems affect: & & \\
\hline Television watching & & & Television watching & & \\
\hline Yes & $2.56(1.61-5.00)$ & .006 & Yes & $2.56(1.43-4.59)$ & .002 \\
\hline No & 1.00 & & No & 1.00 & \\
\hline "Testing blood glucose is difficult" & & & Reading & & \\
\hline Agree & $3.25(1.59-6.66)$ & .001 & Yes & $2.04(1.11-3.76)$ & .022 \\
\hline Disagree & 1.00 & & No & 1.00 & \\
\hline Diet limits social life & $3.28(1.69-6.34)$ & .000 & Driving & & \\
\hline Yes & 1.00 & & Yes & $2.67(1.17-6.11)$ & .020 \\
\hline No & & & No & 1.00 & \\
\hline Leg discomfort affects: & & & Leg discomfort affects: & & \\
\hline Home activities & & & Home activities & & \\
\hline Yes & $5.74(2.88-11.46)$ & .000 & Yes & $5.69(3.04-10.67)$ & .000 \\
\hline No & 1.00 & & No & 1.00 & \\
\hline Wearing preferred shoes & & & Wearing preferred shoes & & \\
\hline Yes & $6.09(3.07-12.07)$ & .000 & Yes & $(1.41-4.53)$ & .002 \\
\hline No & 1.00 & & No & & \\
\hline Sleep & & & Sleep & & \\
\hline Yes & $4.00(2.03-7.89)$ & .000 & Yes & $3.18(1.75-5.78)$ & .000 \\
\hline \multirow[t]{8}{*}{ No } & 1.00 & & No & 1.00 & \\
\hline & & & Diet limits social life & & \\
\hline & & & Yes & $3.19(1.68-6.06)$ & .000 \\
\hline & & & No & 1.00 & \\
\hline & & & "Glucose monitoring is painful" & & \\
\hline & & & Yes & & \\
\hline & & & No & $3.29(1.77-6.12)$ & .000 \\
\hline & & & & 1.00 & \\
\hline Healthcare use factors & & & Healthcare use factors & & \\
\hline Number of ER visits & & & Number of ER visits & $2.00(1.11-3.62)$ & .022 \\
\hline$\geq 1$ & $2.28(1.17-4.44)$ & .016 & $\geq 1$ & 1.00 & \\
\hline 0 & 1.00 & & 0 & & \\
\hline Hospital stays & & & Hospital stays & & \\
\hline$\geq 1$ & $2.03(1.04-3.95)$ & .037 & $\geq 1$ & $2.60(1.41-4.78)$ & .002 \\
\hline 0 & 1.00 & & 0 & 1.00 & \\
\hline Number of doctor visits & $2.76(1.46-5.21)$ & .002 & & & \\
\hline$\geq 1$ per month & 1.00 & & & & \\
\hline \multicolumn{6}{|l|}{$<1$ per month } \\
\hline \multicolumn{6}{|l|}{ Social factors } \\
\hline Family support & $0.50(0.26-0.94)$ & .032 & & & \\
\hline Low & 1.00 & & & & \\
\hline High & & & & & \\
\hline
\end{tabular}

${ }^{*}$ Only variables that were significant individually were included into the logistic regression model.; $P<.05$. CI, confidence interval; OR, odds ratio. 
Table 4. Multivariate Correlates to Clinical Depressive Symptoms by Two Study Samples

\begin{tabular}{|c|c|c|c|c|c|}
\hline \multirow[b]{2}{*}{ Significant Correlates* } & \multicolumn{2}{|c|}{ South Texas } & \multirow[b]{2}{*}{ Significant Correlates* } & \multicolumn{2}{|c|}{ Northern Tamaulipas } \\
\hline & OR (95\% CI) & $P$ & & OR (95\% CI) & $P$ \\
\hline Demographic factors & & & Health factors & & \\
\hline Gender & & & $\begin{array}{l}\text { Leg discomfort interferes with } \\
\text { home activities }\end{array}$ & & \\
\hline Female & $3.51(1.19-10.40)$ & .023 & Yes & $3.82(1.60-9.11)$ & .003 \\
\hline Male & 1.00 & & No & 1.00 & \\
\hline Education & & & Diabetes symptoms & $1.66(1.16-1.59)$ & .000 \\
\hline$<$ High school & $4.16(1.55-11.16)$ & .005 & & & \\
\hline$\geq$ High school & 1.00 & & & & \\
\hline \multicolumn{6}{|l|}{ Health factors } \\
\hline \multicolumn{6}{|l|}{ High Cholesterol } \\
\hline Yes & $0.37(0.15-0.92)$ & .032 & & & \\
\hline No & 1.00 & & & & \\
\hline Diabetes symptoms & $1.27(1.08-1.50)$ & .004 & & & \\
\hline \multicolumn{6}{|c|}{$\begin{array}{l}\text { Leg discomfort interferes with } \\
\text { wearing preferred shoes }\end{array}$} \\
\hline Yes & $3.21(1.11-9.24)$ & .031 & & & \\
\hline No & 1.00 & & & & \\
\hline \multicolumn{6}{|c|}{ "Testing blood glucose is difficult" } \\
\hline Agree & $3.14(1.14-8.66)$ & .027 & & & \\
\hline Disagree & 1.00 & & & & \\
\hline \multicolumn{6}{|c|}{ Healthcare utilization factors } \\
\hline \multicolumn{6}{|c|}{ Number of ER visits } \\
\hline$\geq 1$ & $3.37(1.02-11.12)$ & .046 & & & \\
\hline 0 & 1.00 & & & & \\
\hline
\end{tabular}

*Only variables that were significant individually were included into the logistic regression model.; $P<.05$.

CI, confidence interval; OR, odds ratio.

Note: the Nagelkerke $\mathrm{R}^{2}$ was 0.527 for the model of the US sample and 0.514 for the model of the Mexico sample. These values indicate that a substantial portion (over 50\%) of variation of the depression variable is explained away by the fitted models for both populations. The Hosmer-Lemeshow goodness-of-fit tests for both models were not significant $(P=0.567$ for the US model; $P=$ 0.975 for the Mexico model), which suggest adequate model fitting to the data.

female gender and low levels of education, which is consistent with previous studies. ${ }^{8,23,42,43,48-50} \mathrm{Re}-$ search suggests that low access to education affects health literacy and English proficiency in Hispanic patients with type 2, leading to distress and poorer diabetes self-care. ${ }^{8,51}$

Emergency department visits were also associated with higher levels of depressive symptoms in US respondents. The finding agrees with previous research ${ }^{52-54}$ and underlines the importance of recognizing depression as a risk factor for increasing health care expenditures.

Our study shows that the South Texas respondents who perceived that blood glucose testing was difficult were more likely to report clinical depressive symptoms, which is consistent with previous research. ${ }^{55}$ Diabetes interventions in the border region focusing on self-efficacy and the improvement of skills in self-monitoring of blood glucose may result in positive diabetes-related outcomes. ${ }^{56-58}$

An intriguing finding in our study was that the South Texas participants who reported having high cholesterol were less likely to have clinical depressive symptoms. Although this study did not examine medication intake by respondents, it is possible that this finding might be related to the type of cholesterol medications taken by South Texas patients. Research studying the association between statins therapy and depression is still controversial, ${ }^{59-61}$ but some studies indicate that cholesterollowering drugs are associated with a reduced risk of depression. ${ }^{62,63}$ Further research is warranted to better understand the effects of statins-based med- 
ications on depression among diabetic patients in both the US and Mexican health care systems. Additional research should also investigate if hyperlipidemia should be considered an early marker of depression.

This exploratory study has several limitations. The convenience sample of diagnosed patients with type 2 diabetes limits generalizations and thereby causal inferences cannot be made. In addition, both dependent and independent variables were measured using a self-report instrument, which carries possible intrinsic respondent biases and measurement errors. Another limitation is that this study did not explore if participants were taking antidepressants, which may have introduced respondent biases.

Despite its limitations, this preliminary study makes a significant contribution to the literature by assessing the prevalence and correlates of clinical depressive symptoms in Hispanic patients with type 2 diabetes living on both sides of the Texas Mexico border. To the best of our knowledge this is the first binational study addressing depression and diabetes among border residents. Our findings may have health policy implications. Healthy Border 2010 identifies diabetes and mental health issues as border health priorities. Screening diabetics for depression is of great importance because there is evidence that treatment of depression improves glycemic control ${ }^{64}$ and increases a patient's quality of life. ${ }^{65}$ Healthy Border 2010, however, recognizes that access to mental health services along the US Mexico border is problematic because of a shortage of specialty mental health providers and services. ${ }^{28}$ In addition, differences between both the US and the Mexican health care systems and practices pose barriers to meaningful cooperative health programs that, if successful, could contribute to the health improvement of the border population. ${ }^{66}$ Further research is warranted to examine the feasibility and impact of binational programs involving family practice physicians on both sides of the border in depression screenings among patients with type 2 diabetes.

\footnotetext{
The authors wish to extend their gratitude to Maria Alen, MD, from TAM Health Science Center; Diana Garcia, BS, and Pama Ellis, RN, from the Diabetes Management Center Rio Grande Regional Hospital; Josefa Lopez, MD, and Carolina Rivera, RN, from Hospital General de Reynosa; Marcel Twahira, MD; Juan Campos, MD; Grace Lawson from El Milagro Clinic, for their
}

assistance and insightful input during the design and implementation of this study.

\section{References}

1. Antai-Otong D. Diabetes and depression: pharmacologic considerations. Perspect Psychiatr Care 2007;43:93-6.

2. Egede LE, Zheng D, Simpson K. Comorbid depression is associated with increased health care use and expenditures in individuals with diabetes. Diabetes Care 2002;25:464-70.

3. Katon WJ, Rutter C, Simon G, et al. The association of comorbid depression with mortality in patients with type 2 diabetes. Diabetes Care 2005;28:266872.

4. de Groot M, Doyle T, Hockman E, et al. Depression among type 2 diabetes rural Appalachian clinic attendees. Diabetes Care 2007;30:1602-4.

5. Anderson RJ, Freedland KE, Clouse RE, Lustman PJ. The prevalence of comorbid depression in adults with diabetes: a meta-analysis. Diabetes Care 2001; 24:1069-78.

6. de Groot M, Pinkerman B, Wagner J, Hockman E. Depression treatment and satisfaction in a multicultural sample of type 1 and type 2 diabetic patients. Diabetes Care 2006;29:549-53.

7. Centers for Disease Control and Prevention. Serious psychological distress among persons with diabetes New York City, 2003. MMWR Morb Mortal Wkly Rep 2004;53:1089-92.

8. Spencer MS, Kieffer EC, Sinco BR, et al. Diabetesspecific emotional distress among African Americans and Hispanics with type 2 diabetes. J Health Care Poor Underserved 2006;17(Suppl):88-105.

9. Georgiades A, Zucker N, Friedman KE, et al. Changes in depressive symptoms and glycemic control in diabetes mellitus. Psychosom Med 2007;69: $235-41$.

10. Centers for Disease Control and Prevention. Fact sheet. Prevalence of diabetes among Hispanics in six US geographic locations. 2005. Available at http://www.cdc.gov/diabetes/pubs/factsheets/ hispanic.htm. Accessed 13 March 2008.

11. Prevalence of diabetes among Hispanics-selected areas, 1998-2002. MMWR Morb Mortal Wkly Rep 2004;53:941-4.

12. Simon P, Zeng Z, Wold C, Fielding J, Burrows N. Diabetes among Hispanics Los Angeles County. California, 2002-2003. MMWR Morb Mortal Wkly Rep 2003;52:1152-5.

13. Caballero AE. Diabetes in the Hispanic or Latino population: genes, environment, culture, and more. Curr Diab Rep 2005;5:217-25.

14. Lavery LA, Armstrong DG, Wunderlich RP, Tredwell J, Boulton AJ. Diabetic foot syndrome: evaluating the prevalence and incidence of foot pathology in Mexican Americans and non-Hispanic whites from a 
diabetes disease management cohort. Diabetes Care 2003;26:1435-8.

15. Harris MI, Klein R, Cowie CC, Rowland M, ByrdHolt DD. Is the risk of diabetic retinopathy greater in non-Hispanic blacks and Mexican Americans than in non-Hispanic whites with type 2 diabetes? A US population study. Diabetes Care 1998;21:1230-5.

16. Harris M, Eastman R, Cowie C. Symptoms of sensory neuropathy in adults with NIDDM in the US population. Diabetes Care 1993;16:1446-52.

17. Pan-American Health Organization, The Centers for Disease Control and Prevention. The USMexico Border Diabetes Prevention and Control Project. First report of results. Available at http:// www.fep.paho.org/english/publicaciones/Diabetes/ Diabetes\%20first\%20report\%20of\%20Results.pdf. Accessed 13 March 2008.

18. Centers for Disease Control and Prevention. QuickStats: Diabetes death rate* for Hispanics $†$ compared with Non-Hispanic Whites United States versus counties along the US-Mexico border, 2000-2002. MMWR 2006;55:882.

19. Rull JA, Aguilar-Salinas CA, Rojas R, Rios-Torres JM, Gomez-Perez FJ, Olaiz G. Epidemiology of type 2 diabetes in Mexico. Arch Med Res 2005;36: 188-96.

20. Olaiz-Fernández G, Rojas R, Aguilar-Salinas CA, Rauda J, Villalpando S. Diabetes mellitus en adultos mexicanos. Resultados de la Encuesta Nacional de Salud 2000. Salud Pub Mex 2007;29(Suppl 3): S331-7.

21. Goodnick PJ, Henry JH, Buki VM. Treatment of depression in patients with diabetes mellitus. J Clin Psychiatry 1995;56:128-36.

22. de Groot M, Jacobson AM, Samson JA, Welch G. Glycemic control and major depression in patients with type 1 and type 2 diabetes mellitus. J Psychom Res 1995;46:425-35.

23. Fisher L, Chesla CA, Mullan JT, Skaff MM, Kanter RA. Contributors to depression in Latino and European-American patients with type 2 diabetes. Diabetes Care 2001;24:1751-7.

24. Shah ZC, Huffman FG. Depression among Hispanic women with type 2 diabetes. Ethn Dis 2005;15:68590.

25. Garcia de Alba Garcia JE, Dallo FJ, Salcedo Rocha $\mathrm{AL}$, et al. The relative effect of self-management practices on glycaemic control in type 2 diabetic patients in Mexico. Chronic Illn 2006;2:77-85.

26. Gross R, Olfson M, Gameroff MJ, et al. Depression and glycemic control in Hispanic primary care patients with diabetes. J Gen Intern Med 2005;20: 460-6.

27. Killilea T. Long-term consequences of type 2 diabetes mellitus: economic impact on society and managed care. Am J Manag Care 2002;8(Suppl):S441-9.

28. United States-Mexico Border Health Commission. Healthy border 2010. An agenda for improving health on the United States-Mexico border. El Paso (TX): United States-Mexico Border Health Commission; 2003.

29. Boyd JH, Weissman MM, Thompson W, Myers JK. Screening for depression in a community sample. Arch Gen Psychiat 1982;39:1195-200.

30. Roberts RE, Vernon SW. The Center for Epidemiologic Studies Depression Scale: its use in a community sample. Am J Psychiatry 1983;140:41-6.

31. Lustman PJ, Clouse RE. Depression in diabetic patients: the relationship between mood and glycemic control. J Diabetes Complications 2005;19:113-22.

32. Garcia M, Marks G. Depressive symptomatology among Mexican-American adults: an examination with the CES-D Scale. Psychiatry Res 1989;27:13748.

33. Roberts RE. Reliability of the CES-D scale in different ethnic contexts. Psychiatry Res 1980;2:12534.

34. Powers MG. Measures of socioeconomic status: an introduction. In: Powers MG (ed). Measures of socioeconomic status: current issues. Boulder (CO): Westview; 1981:1-28.

35. Krieger N, Williams DR, Moss NE. Measuring social class in U.S. public health research: concepts, methodologies, and guidelines. Annu Rev Public Health 1997;18:341-78.

36. Marin G, Sabogal F, Marin BV, Otero-Sabogal R, Perez-Stable EJ. Development of a short acculturation scale for Hispanics. Hispanic Behav Sci 1987;9: 183-205.

37. Hoogwerf B. Diabetes Form 2.1. Minneapolis (MN): InterStudy; 1989.

38. Glasgow R, Toobert D. Social environment and regimen adherence among type II diabetic patients. Diabetes Care 1988;11:377-86.

39. SPSS Inc. Statistical Package for the Social Sciences (SPSS) for Windows, Rel. 13.0 2004. Chicago (IL): SPSS, Inc.; 2004.

40. Black SA, Markides KS, Miller TQ. Correlates of depressive symptomatology among older community-dwelling Mexican Americans: the Hispanic EPESE. J Gerontol B Psychol Sci Soc Sci 1998;53: S198-208.

41. Black SA. Increased health burden associated with comorbid depression in older diabetic Mexican Americans. Results from the Hispanic Established Population for the Epidemiologic Study of the Elderly survey. Diabetes Care 1999;22:56-64.

42. Téllez-Zenteno JF, Cardiel MH. Risk factors associated with depression in patients with type 2 diabetes mellitus. Arch Med Res 2002;33:53-60.

43. Garduño-Espinosa J, Téllez-Zenteno JF, Hernández-Ronquillo L. Frequency of depression in patients with diabetes mellitus type 2. Rev Invest Clin 1998;50:287-91.

44. McKellar JD, Humphreys K, Piette JD. Depression increases diabetes symptoms by complicating pa- 
tients' self-care adherence. Diabetes Educ 2004;30: 485-92.

45. Sacco WP, Yanover T. Diabetes and depression: the role of social support and medical symptoms. J Behav Med 2006;29:523-31.

46. Ludman EJ, Katon W, Russo J, et al. Depression and diabetes symptom burden. Gen Hosp Psychiatry 2004;26:430-6.

47. Ciechanowski PS, Katon WJ, Russo JE, Hirsch IB. The relationship of depressive symptoms to symptom reporting, self-care and glucose control in diabetes. Gen Hosp Psychiatry 2003;25:246-52.

48. Katon W, von Korff M, Ciechanowski P, et al. Behavioral and clinical factors associated with depression among individuals with diabetes. Diabetes Care 2004;27:914-20.

49. Fisher L, Chesla CA, Skaff MM, Mullan JT, Kanter RA. Depression and anxiety among partners of European-American and Latino patients with type 2 diabetes. Diabetes Care 2002;25:1564-70.

50. Blazer DG, Moody-Ayers S, Craft-Morgan J, Burchett B. Depression in diabetes and obesity: racial/ ethnic/gender issues in older adults. J Psychosom Res 2002;53:913-6.

51. Heisler M, Piette JD, Spencer M, Kieffer E, Vijan S. The relationship between knowledge of recent HbAlc values and diabetes care understanding and self-management. Diabetes Care 2005;28:816-22.

52. Egede LE. Major depression in individuals with chronic medical disorders: prevalence, correlates and association with health resource utilization, lost productivity and functional disability. Gen Hosp Psychiatry 2007;29:409-16.

53. Husaini BA, Hull PC, Sherkat DE, et al. Diabetes, depression, and healthcare utilization among African Americans in primary care. J Natl Med Assoc 2004; 96:476-84.

54. Kalsekar ID, Madhavan SM, Amonkar MM, Scott V, Douglas SM, Makela E. The effect of depression on health care utilization and costs in patients with type 2 diabetes. Manag Care Interface 2006;19:39-46.

55. Franciosi M, Pellegrini F, De Berardis G, et al. The impact of blood glucose self-monitoring on metabolic control and quality of life in type 2 diabetic patients: an urgent need for better educational strategies. Diabetes Care 2001;24:1870-7.

56. Siebolds M, Gaedeke O, Schwedes U. Self-monitoring of blood glucose-psychological aspects relevant to changes in HbAlc in type 2 diabetic patients treated with diet or diet plus oral antidiabetic medication. Patient Educ Couns 2006;62:104-10.

57. Halimi S, Wion-Barbot N, Lambert S, Benhamou P. Self-monitoring of blood glucose in type 2 diabetic patients. What could we propose according to their treatment? Diabetes Metab 2003;29(2 Pt 2):S26-30.

58. Schwedes U, Siebolds M, Mertes G. Meal-related structured self-monitoring of blood glucose: effect on diabetes control in non-insulin-treated type 2 diabetic patients. Diabetes Care 2002;25:1928-32.

59. Brunner J, Parhofer KG, Schwandt P, Bronisch T. Cholesterol, essential fatty acids, and suicide. Pharmacopsychiatry 2002;35:1-5.

60. Tatley M, Savage R. Psychiatric adverse reactions with statins, fibrates and ezetimibe: implications for the use of lipid-lowering agents. Drug Saf 2007;30: 195-201.

61. Golomb BA, Criqui MH, White HL, Dimsdale JE. The UCSD Statin Study: a randomized controlled trial assessing the impact of statins on selected noncardiac outcomes. Control Clin Trials 2004;25:178202.

62. Tsai SJ. Statins may enhance the proteolytic cleavage of proBDNF: implications for the treatment of depression. Med Hypotheses 2007;68:1296-9.

63. Young-Xu Y, Chan KA, Liao JK, Ravid S, Blatt CM. Long-term statin use and psychological well-being. J Am Coll Cardiol 2003;42:690-7.

64. Lustman PJ, Williams MM, Sayuk GS, Nix BD, Clouse RE. Factors influencing glycemic control in type 2 diabetes during acute- and maintenance-phase treatment of major depressive disorder with bupropion. Diabetes Care 2007;30:459-66.

65. Kruse J, Petrak F, Herpertz S, Albus C, Lange K, Kulzer B. Diabetes and depression-a life-endangering interaction. Z Psychosom Med Psychother 2006; 52:289-309.

66. Homedes N, Ugalde A. Globalization and health at the United States-Mexico border. Am J Public Health 2003;93:2016-22. 